\title{
Benign Multifocal Stenosing Ulceration, or CMUSE---A Rarely Diag- nosed Small Intestinal Disorder
}

\author{
Hugh James Freeman* \\ Department of Medicine (Gastroenterology), University of British Columbia, Vancouver, BC, Canada
}

\section{Article Info}

\section{Article Notes}

Received: May 12, 2016

Accepted: June 24, 2016

\section{*Correspondence:}

Dr. Hugh Freeman, Gastroenterology, UBC Health Sciences Center Hospital, 2211 Wesbrook Mall, Vancouver, BC, Canada V6T 1W5

E-mail: hugfree@shaw.ca

(C) 2016 Freeman HJ. This article is distributed under the terms of the Creative Commons Attribution 4.0 International License.

\section{Keywords}

Ulcer

Stenosis

Intestinal Diseases

Small Intestine

Crohn's Disease

\section{ABSTRACT}

A rarely diagnosed clinical and pathological disorder was historically characterized by multiple benign small intestinal ulcers, involving the mucosa and, occasionally, the submucosa of the small intestine, and histopathologically by non-specific inflammatory changes without granulomas. These early reports also noted that recurrent episodes of abdominal pain often developed due to obstructive events, sometimes associated with localized stricture formation. This usually responded to steroid treatment, intestinal resection, or both. Recent advances owing largely to emerging imaging methods have provided added criteria for separation of this entity from other disorders, including Crohn's disease and medication-related small bowel ulceration. Most important, recent long-term follow-up studies have suggested a potential for confusion with other functional or motility-based clinical disorders and emphasize the likelihood of a much more benign clinical course.

For more than a half century, descriptive accounts (largely in the French literature $)^{1-8}$ noted a disorder characterized clinically by intermittent episodes of small intestinal obstruction due to benign multifocal ulceration, sometimes associated with stricture formation. Some initial reports suggested that the entity consisted of shallow mucosal and submucosal ulcers mainly localized in the jejunum and proximal ileum, different from the typical distribution of other inflammatory processes of the small intestine with ulcers, such as Crohn's disease ${ }^{9}$. In retrospect, some observations may also have reflected, in large part, inherent limitations of imaging modalities available used then to evaluate the small intestine, specifically endoscopic imaging coupled with radiologic contrast studies of the small bowel. In recent years, primarily using new methods, including capsule and double-balloon enteroscopy ${ }^{10}$, a more precise appreciation for the clinical spectrum and the expanded extent and nature of this pathological process has developed.

Early reports often termed the disorder "cryptogenic multifocal ulcerous stenosing enteritis (CMUSE)", sometimes responsive to steroids, and if needed, surgical resection of an involved small bowel segment. Ulceration appeared to be limited to the mucosa, perhaps extending into the submucosa, not transmural, while the histopathological changes were characterized by non-specific inflammation not granulomas, suggesting a different, but not necessarily exclusive pathogenesis from some with Crohn's disease. CMUSE was believed to be distinctive and apart from abdominal pain and associated obstructive events, usually uncomplicated. As 
previously noted ${ }^{9}$, clinical events involving the intestine, such as perforation, fistula development or predilection for superimposed malignancy rarely, if ever, seemed to occur.

\section{Clinical Features}

Early retrospective reports noted the high frequency of clinical presentation with abdominal symptoms. Usually, abdominal pain was most prominent, often associated with ulceration and stenotic obstruction. The pain was often described as intermittent, but in some, up to $40 \%$, pain was persistent ${ }^{7}$. Sometimes, weight loss, fever and malaise were also present and, rarely, even joint symptoms were described. Endoscopic, and even direct visualization of resected intestine, reveal multiple small discrete, often circular (rather than linear) ulcerations in the small intestinal mucosa (from 1 to 25 in number with a mean of 8 ), predominately superficial, usually involving only the mucosa, but sometimes with submucosal extension. In some, strictures were evident and the intervening small bowel mucosa appeared normal. Of course, these features were largely based on earlier imaging methods and review of surgically-resected specimens, often after failure to respond to steroid treatment, estimated to be up to $50 \%{ }^{7}$. In some, a second resection or even multiple resections were required. In one report ${ }^{7}$, a link with vasculitis and C2 complement deficiency was also described. In recent years, however, new imaging methods with double-balloon endoscopy and biopsies have suggested a broader clinical presentation with significant implications, particularly for treatment. Biopsies may show non-granulomatous inflammation. Some also have iron deficiency anemia and protein-losing enteropathy ${ }^{11}$. Particularly interesting are recent reports of PLA2G4A gene mutations suggesting a genetic cause in some with this disorder ${ }^{12-14}$. Further work and evaluation of genetic risk factors are needed.

\section{Differential Diagnosis}

Other disorders can cause multifocal small intestinal ulceration. These have been listed elsewhere ${ }^{15}$ and require exclusion, particularly Crohn's disease involving the small intestine $^{9}$. Idiopathic ulcerative jejunoileitis is another distinctive small bowel disorder, initially described to complicate the clinical course of celiac disease ${ }^{16}$ while superficial ulceration in this setting may also represent a difficult-to-diagnose lymphoma ${ }^{17}$. Infections may also cause ulcers but most (eg., Campylobacter, Shigella, Yersinia, Salmonella) are self-limited and resolve without stricture formation, while others (eg., tuberculosis, cytomegalovirus) may persist, often in the setting of an immune compromised state. Medications have become increasingly recognized, especially non-steroidal antiinflammatory agents. These may induce ulcers, strictures and development of so-called diaphragm disease in the small intestine. More recently, however, diaphragm disease also been recorded in the absence of these agents ${ }^{18,19}$ and some investigators have suggested features that might permit differentiation of diaphragm disease with or without non-steroidal anti-inflammatory drugs ${ }^{20}$. These drugs may also cause a mucosal inflammatory process without ulceration ${ }^{21}$, similar to the changes of untreated celiac disease. Indeed, an extensive list of modern pharmaceutical agents have now been detailed that may cause small bowel mucosal injury documented with small intestinal mucosal biopsy, sometimes with localized mucosal ulceration and these have been recently detailed elsewhere ${ }^{22,23}$. Peptic erosions and ulcers may also develop with a gastrinoma in the Zollinger-Ellison syndrome or with heterotopic functioning gastric mucosa in a congenital Meckel's type diverticulum. Small bowel ulcers may also result from traumatic injury, post-surgical changes, especially near stomas, endoscopic injury or external abdominal trauma including seatbelt injuries with motor vehicle accidents, or swallowed foreign bodies. A number of systemic disorders with vascular changes causing ischemia may also result in multifocal ulceration (eg., thromotic diseases, Dego's disease, pseudoxanthoma elasticum, myeloproliferative disorders, anti-thrombin III deficiency and vasculitis associated with collagen vascular disorders.

\section{Further Directions for the Future}

Although the early literature suggested that some with this rarely diagnosed disorder could be treated with steroids and would be steroid-responsive, some still required localized intestinal resection. Others appear not to respond to steroids, and other medications, including immunosuppressive therapy, have been tried ${ }^{24}$. Temporizing with endoscopic dilatation may be helpful in some cases ${ }^{25}$. It is also conceivable that some patients might respond to symptomatic treatment with other agents, including biologicals, sometimes used in management of other ulcerating small intestinal diseases, like Crohn's disease. A recent case treated with infliximab has been reported $^{25}$. Additional information is needed, especially in a well-defined population group.

Most intriguing is a recent report from $\mathrm{China}^{26}$. In their experience with long-term follow-up of a small group of patients evaluated and treated for several years with a presumptive diagnosis of a functional bowel disorder as a cause for symptoms, small intestinal ulcers were eventually detected with direct ileoscopic imaging. Empirical therapies could not be directly correlated with the presence of ulcers. Nevertheless, prolonged follow-up demonstrated that no patient ultimately ever experienced a significant clinical exacerbation of their disease or a complication, and none required surgical intervention. Given this information, it is conceivable that this disorder is more common than currently appreciated with routine imaging studies and may be confused with functional 
bowel disorders that usually run an entirely benign clinical course in most patients. Additional studies of this entity in larger patient numbers with multifocal intestinal ulcers (CMUSE) are needed.

\section{References}

1. Rocha A, Artigas V. Stenosing ulcerous disease of the jejuno-ileum. Arch Mal Appar Dig Mal Nutr. 1959; 48: 1230-1236.

2. Debray C, Besancon F, Hardouin JP, Martin E, Marche C, Khoury K Cryptogenic plurifocal ulcerative stenosing enteritis. Arch Mal Appar Dig Mal Nutr. 1964; 53: 193-206.

3. Doutre LP, Paccalin J, Perissat J, Traissac FJ. Plurifocal ulcerous stenosing enteritis. A further case. Arch Fr Mal App Dig. 1966; 55: $537-$ 540 .

4. Chagnon JP, Devars du Mayne JF, Marche C, Vissuzaine C, Cerf M Multifocal cryptogenic stenosing enteritis: an autonomous entity? J Gastroenterol Clin Biol. 1984; 8: 808-813.

5. Gaucher P, Bigard MA, Champigneulle, Colin D. Cryptogenic multifocal stenosing enteritis: a new case. J Gastroenterol Clin Biol. 1985; 9: 453.

6. Bokemeyer B, Schmidt FW. Galanski M. Cryptogenic multifocal stenosing enteritis. Z Gastroenterol. 1987; 25: 745-748.

7. Perlemuter G, Chaussade S, Soubrane O, Degoy A, Louvel A, Barbet P, et al. Multifocal stenosing ulcerations of the small intestine revealing vasculitis associated with C2 deficiency. Gastroenterology. 1996; 110 1628-1632.

8. Spencer H, Kitsanta P, Riley S. Cryptogenic multifocal ulcerous stenosing enteritis. J R Soc Med. 2004; 97: 538-540.

9. Freeman HJ. Application of the Montreal classification for Crohn's disease to a single clinician database of 1015 patients. Can J Gastroenterol. 2007; 21: 363-366.

10. Chang DK, Kim JJ, Choi H, Eun CS, Han DS, Byeon JS, et al. Double balloon endoscopy in small intestinal Crohn's disease and other inflammatory diseases such as cryptogenic multifocal ulcerous stenosing enteritis (CMUSE). Gastrointest Endosc. 2007; 66 (3 Suppl): S96-S98.

11. Kahoutova D, Bartova J, Tacheci I, Rejchrt S, Repak R, Kopacova M, et al. Cryptogenic multifocal ulcerous stenosing enteritis: a review of the literature. Gastroenterol Res Pract. 2013.

12.Vasco PG, Rodriguez GF. Cryptogenia multifocal ulcerous enteritis: an entity on its own as a cause of abdominal pain, iron deficiency anemia and protein-losing enteropathy. Rev Clin Esp. 2014; 214: 26-30.

13.Adler DH, Cogan JD, Phillips 3rd JA, Schnetz-Boutaud N, Milne GL,
Iverson T, et al. Inherited human cPLA(2alpha) deficiency is associated with impaired eicosanoid biosynthesis, small intestinal ulceration, and platelet dysfunction. J Clin Invest. 2008; 118: 2121-2131.

14. Brooke MA, Longhurst HJ, Plagnoi V, Kirkby NS, Mitchell JA, Ruschendorf F, et al. Cryptogenic multifocal ulcerous stenosing enteritis associated with homozygous deletion mutations in cytosolic phospholipase A2alpha. Gut. 2014; 63: 96-104.

15. Freeman HJ. Multifocal stenosing ulceration of the small intestine. World J Gastroenterol. 2009; 15: 4883-4885.

16.Jeffries GH, Steinberg $\mathrm{H}$, Sleisenger $\mathrm{MH}$. Chronic ulcerative (nongranulomatous) jejunitis. Am J Med. 1968; 44: 47-59.

17. Freeman HJ, Weinstein WM, Shnitka TK, Piercey JR, Wensel RH. Primary abdominal lymphoma. Presenting manifestation of celiac sprue or complicating dermatitis herpetiformis. Am J Med. 1977; 63: 585-594.

18.Santolaria S, Cabezali R, Ortego J, Castiella T, Salinas JC, Lanas A. Diaphragm disease of the small bowel: a case without apparent nonsteroidal anti-inflammatory drug use. J Clin Gastroenterol. 2001; 32: 344-346.

19. Matsumoto T, Iida M, Matsui T, Yao T, Watanabe H, Yao T, et al. Nonspecific multiple ulcers of the small intestine unrelated to a nonsteroidal anti-inflammatory drugs. J Clin Pathol. 2004; 57: 1145-1150.

20.Chung SH, Jo Y, Ryu SR, Ahn SB, Son BK, Kimn SH, et al. Diaphagm disease compared to cryptogenic multifocal ulcerous stenosing enteritis. World J Gastroenterol. 2011; 17: 2873-2876.

21. Freeman HJ. Sulindac-associated small bowel lesion. J Clin Gastroenterol. 1986; 8: 569-571.

22. Freeman HJ. Drug-induced sprue-like intestinal disease. International J Celiac Dis. 2014; 2: 49-53.

23. Freeman HJ. Olmesartan enteropathy. International J Celiac Dis. 2016; 4: 24-26.

24. Kim CW, Yu CS, Yoon YS, Yoon SN, Lim SB, Kim JC. Steroid-refractory cryptogenic multifocal ulcerous stenosing enteritis. Am J Surg. 2011; 202: e48-51.

25.De Schepper H, Macken E, Van Marck V, Spinhoven M, Pelckmans $P$, Moreels T. Infliximab induces remission in cryptogenic multifocal ulcerous stenosing enteritis: first case. World J Gastroenterol. 2013; 19: $1661-1664$

26.Wang W, Wang Z, Yang Y, Linghu E, Lu Z. Long-term follow-up of nonspecific small bowel ulcers with a benign course and no requirement for surgery: is this a distinct group? BMC Gastroenterol. 2011; $11: 51$. 